\title{
Couple/family therapy for posttraumatic stress disorder: Review to facilitate interpretation of VA/DOD Clinical Practice Guideline
}

\author{
Candice M. Monson, PhD; ${ }^{1-2 *}$ Alexandra Macdonald, PhD; ${ }^{3}$ Amy Brown-Bowers ${ }^{1}$ \\ ${ }^{1}$ Ryerson University, Toronto, Ontario, Canada; ${ }^{2}$ Department of Veterans Affairs (VA) National Center for PTSD, \\ Women's Health Sciences Division, Boston, MA; ${ }^{3}$ VA National Center for PTSD, Behavioral Science Division, and \\ Boston University School of Medicine, Boston, MA
}

\begin{abstract}
A well-documented association exists among Veterans’ posttraumatic stress disorder (PTSD) symptoms, family relationship problems, and mental health problems in partners and children of Veterans. This article reviews the recommendations regarding couple/family therapy offered in the newest version of the Department of Veterans Affairs (VA)/Department of Defense (DOD) VA/DOD Clinical Practice Guideline for Management of Post-Traumatic Stress. We then provide a heuristic for clinicians, researchers, and policy makers to consider when incorporating couple/family interventions into Veterans' mental health services. The range of research that has been conducted on couple/family therapy for Veterans with PTSD is reviewed using this heuristic, and suggestions for clinical practice are offered.
\end{abstract}

Key words: caregiver burden, clinical practice guidelines, cognitive-behavioral therapy, couple/family therapy, emotionally focused couple therapy, mental health, PTSD, rehabilitation, strategic approach therapy, Veterans.

\section{INTRODUCTION}

To their credit and our benefit, Veterans and their families have been the predominant contributors to our knowledge about the role of posttraumatic stress disorder (PTSD) symptoms in family functioning and vice versa. This research documents a clear and convincing association between PTSD symptoms and a range of family problems (see Monson et al. [1] for review). In addition, Veterans' PTSD symptoms have been associated with a myriad of individual mental health problems in spouses and children (see Renshaw et al. [2] for review). Yet, research on couple/ family therapies for Veterans with PTSD has lagged behind individual psychotherapy treatment outcome efforts. This is in spite of research showing that Veterans desire greater family involvement in their treatment (e.g., Batten et al. [3]) and the presence of significant mental health problems in Veterans' loved ones who may individually profit from family therapy. In addition, treatments for PTSD do not necessarily improve couple and family functioning (e.g.,

\footnotetext{
Abbreviations: $\mathrm{BCT}=$ behavioral couple therapy, $\mathrm{BFT}=$ behavioral family therapy, СBCT $=$ cognitive-behavioral conjoint therapy, $\mathrm{CPG}=$ Clinical Practice Guideline, $\mathrm{CSO}=$ concerned significant other, DOD $=$ Department of Defense, DTE = directed therapeutic exposure, EFCT for Trauma = emotionally focused couple therapy for trauma, LMC = lifestyle management course, PTSD = posttraumatic stress disorder, RCT = randomized controlled trial, SAFE = Support and Family Education (Program), SAT = strategic approach therapy, VA = Department of Veterans Affairs.

*Address all correspondence to Candice M. Monson, PhD; Department of Psychology, Ryerson University, 350 Victoria St, Toronto, ON M5B 2K3 Canada; 416-979-5000, ext 6209. Email: candice.monson@psych.ryerson.ca http://dx.doi.org/10.1682/JRRD.2011.09.0166
} 
Glynn et al. [4]; Lunney and Schnurr [5]; Monson et al. ${ }^{*}$ ) and negative family interactions have been associated with poorer individual cognitive-behavioral treatment outcomes [6-7]. To further treatment and research efforts in this area, this article reviews the recommendations regarding couple/ family therapy offered in the newest version of the Department of Veterans Affairs (VA)/Department of Defense (DOD) VA/DOD Clinical Practice Guideline for Management of Post-Traumatic Stress. [8] and then provides a heuristic for clinicians, researchers, and policy makers to consider when incorporating couple/family interventions into Veterans' mental health services. Then, the range of research that has been conducted on family therapy for PTSD with Veterans is reviewed using this heuristic and suggestions for clinical practice are offered.

\section{METHODS}

Recommendations regarding couple/family therapy offered in the newest version of the VA/DOD Clinical Practice Guideline for Management of Post-Traumatic Stress were reviewed. Review of the empirical studies on which these guidelines were based resulted in the development of a heuristic that organizes these interventions based on an interaction of their stated focus of improving (1) relationship functioning and/or (2) PTSD. Following this, a literature search was done on couple/family interventions for PTSD using PsychInfo, MEDLINE, ERIC (Education Resources Information Center), and GoogleScholar databases. The following search terms were used: couple therapy, conjoint therapy, family therapy, interpersonal, PTSD, and trauma.

\section{RESULTS}

\section{VA/DOD Clinical Practice Guideline Regarding Couple/Family Therapy}

In the clinical practice guideline (CPG), family therapy was given an overall "Insufficient" rating for the treatment of PTSD; this rating indicates "The evidence is insufficient

\footnotetext{
*Monson CM, Macdonald A, Vorstenbosch V, Shnaider P, Goldstein ESR. Changes in social adjustment with cognitive processing therapy: effects of treatment and association with PTSD symptom change. J Trauma Stress. 2012. In press.
}

to recommend for or against routinely providing the intervention. Evidence that the intervention is effective is lacking or poor quality, or conflicting, and the balance of benefits to harms cannot be determined" [8, p. 202]. The supporting evidence offered for this conclusion includes three studies: Devilly [9], Glynn et al. [4], and Monson et al. [10]. Upon review of these studies, the CPG summarizes that "BFT [behavioral family therapy] did not significantly improve the PTSD symptoms and was inferior to other psychotherapies" [8, p. 144]. The level of evidence was rated as "I = At least one properly done RCT [randomized controlled trial], "and the quality of evidence was rated 'fair-poor."' The CPG concludes "There is insufficient evidence to recommend for or against Family or Couples Therapy as a firstline treatment for PTSD. Family or Couples therapy may be considered in managing PTSD-related family disruption or conflict, increasing support, or improving communication" [8, p. 118].

Although we agree with the ultimate overall "I" rating and subratings of level and strength of evidence, we disagree with the conclusion drawn from the studies reviewed. In addition, there are other studies not considered in the CPG that we believe are important to consider when drawing a conclusion about the benefits and costs of couple/family therapy for PTSD, which we systematically review in the next section. Our concerns with the conclusion offered from the literature reviewed in the CPG are outlined here.

Glynn et al. conducted one of the most rigorous tests of family therapy for PTSD to date [4]. In their study, they used an additive research design to test the incremental utility of a specific BFT focused on improving communication and problem-solving skills [11]. In this trial, the provision of BFT followed an individually delivered psychotherapy, directed therapeutic exposure (DTE), which focused on repeated narrative trials and cognitive restructuring of two traumatic memories [12]. Forty-two Veterans and one of their family members (89\% conjugal partners) were randomized to DTE alone, DTE $\rightarrow$ BFT, or a waiting list. Outcomes reported were clinician-rated PTSD symptoms and patient and family member reports of family functioning. Participants in both DTE and DTE $\rightarrow$ BFT improved more than those assigned to the waiting list on what the authors refer to as "positive" PTSD symptoms (i.e., reexperiencing, hyperarousal) but not the "negative" symptoms of PTSD (i.e., avoidance, numbing) or social adjustment. Participants who completed DTE $\rightarrow$ BFT also showed statistically significantly more improvements in 
interpersonal problem-solving than did participants who received DTE only. When interpreting the results of this trial, note that BFT followed individual DTE; BFT alone was not directly compared with DTE.

The two other studies on which the CPG was based were uncontrolled trials that did not include randomization or a control or comparison condition. They generally did not include methodologically rigorous elements of controlled psychotherapy studies, such as independent and blinded clinician assessment of PTSD symptoms, assessment of longer-term outcomes, fidelity to treatment assessment, or reliability assessment of clinician assessors. Devilly described the results of a program evaluation study of Australian combat Veterans and their partners who participated in an intensive weeklong residential group intervention that included psychoeducation about PTSD and symptom management techniques [9]. At follow-up, both Veterans and their partners reported statistically significant reductions in anxiety, depression, and general stress; Veterans reported a significant reduction in PTSD symptoms. Small and nonsignificant improvements were also observed for anger and quality of life, but not for relationship satisfaction.

The other study tested an early version of cognitivebehavioral conjoint therapy (CBCT) for PTSD [13], which is designed to simultaneously ameliorate PTSD symptoms and enhance relationship functioning. In a sample of seven couples in which one member of the couple was a male Vietnam Veteran with PTSD, Monson et al. found statistically significant and large effect size improvements in clinicians' and partners' ratings of Veterans' PTSD symptoms from pre- to posttreatment [10]. The Veterans reported moderate effect size improvements in PTSD and statistically significant and large improvements in depression, general anxiety, and social functioning. Wives reported large effect size improvements in their relationship satisfaction, general anxiety, and social functioning [14].

Based on a review of these three studies (and other studies completed to date), no couple/family therapy has ever been directly compared with another psychotherapy for PTSD. Thus, given the available evidence, it is not possible to conclude that couple/family therapy alone is inferior to other therapies as indicated in the CPG. Moreover, Devilly [9] and Monson et al. [10] found significant improvements in PTSD symptoms as a result of a partnerinvolved treatment. We think a more accurate conclusion might be that some evidence suggests that the class of cognitive-behavioral couple interventions may improve PTSD symptoms and intimate relationship functioning.

\section{Heuristic for Understanding Treatment Targets}

The CPG's recommendation regarding couple/family therapy underscores one consideration when evaluating couple/family treatments for PTSD: What is the treatment target? Is it improvements in family functioning? PTSD symptoms? Both? To further policy, practice, and research in this area, we offer a heuristic to consider when making decisions about how to incorporate family members into Veterans' treatment (Figure). This heuristic organizes interventions based on an interaction of their stated focus of improving (1) relationship functioning and/or (2) PTSD. All the interventions discussed in this article fall into the broader category of couple/family therapy in that they address the close relational system in which the individual exists. Our heuristic expands Baucom et al.'s [15] prior conceptualization of empirically supported couple and family interventions for marital distress and adult mental health problems by considering the range of concerned significant others (CSOs) such as parents, siblings, close friends, and extended family who might be considered "family" by the patient and included in treatment to enhance its efficacy (i.e., not just focused on couple distress). Drawing on research in the substance use disorder literature documenting the use of CSOs in treatment engagement [16], we also consider interventions that are not designed to explicitly improve PTSD or another mental health condition or relationship functioning, but may be used to enhance treatment delivery by increasing engagement or facilitating the provision of other treatments.

The specific objectives and hoped-for outcomes of these interventions differ based on the way that family is

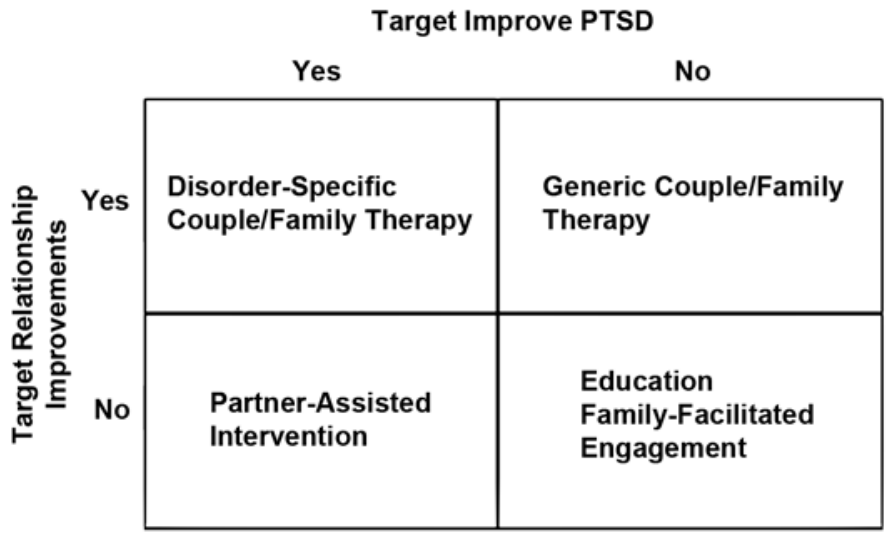

Figure.

Heuristic for understanding target of different couple/family interventions for posttraumatic stress disorder (PTSD). 
included; the interventions differ based on their focus on the relationship and/or PTSD symptoms. In addition, some of these interventions have also yielded improvements in family members' health and well-being. Some interventions specifically target the marital- or romantic relationship within the family (i.e., couple therapy), while others include other family members. We have attempted to refer to the format (i.e., couple or family) of therapy as described in the publications by the authors. The minimum inclusion criterion for review was objective data analyzed at the group level; theoretical writings and individual case studies were not included in this review.

First, as demonstrated in the lower right-hand quadrant of the Figure, family members may be used to engage Veterans in assessment and treatment or to educate them about PTSD and the rationale of evidencebased treatments. In this way, improvements in PTSD symptoms or relationship functioning are not the targets of the intervention; rather, engagement and/or education are the goals. These interventions may include strategies taught to CSOs to increase the likelihood of Veterans seeking treatment for PTSD and its common comorbidities and/or education provided to CSOs about the symptoms of PTSD and the rationale for various evidencebased treatments.

Second, family members may be involved in what we term "generic family therapy" with the Veteran. This approach has the parsimonious goal of improving relationship functioning. Improvements in relationship functioning may, in fact, improve a Veteran's PTSD symptoms and the health and well-being of family members by decreasing the stress in their interpersonal environment. However, the objective of the family members' inclusion is to improve the relational milieu in which the Veteran and his or her family exist and does not specifically target the mechanisms thought to maintain the individual disorder.

Third, family members may be involved in partnerassisted interventions in which the family members serve as a surrogate coach or therapist for the Veteran. These interventions aim to promote the Veteran's treatment by educating family members about the rationale for therapy so that they can actively support the Veteran in treatment or enhance therapies typically delivered in an individual format. Relational issues are not the focus of these interventions; supported delivery of the individual interventions is the goal.

Fourth, family members may be included in disorderspecific family therapies, which are therapies that have been specifically developed to simultaneously improve relationship functioning as well as PTSD. In this way, relationship functioning and individual-level symptoms of PTSD are simultaneous targets for the interventions. To be maximally efficient in the therapy, the interventions are generally developed to target mechanisms known to contribute to the development and maintenance of PTSD and relational distress.

\section{Efficacy of Interventions by Type of Involvement Strategy}

The Table includes a summary of evidence regarding treatment efficacy related to the stated treatment target (i.e., individual PTSD outcome and/or relationship adjustment outcome). Consistent with the description above, we begin with those interventions designed to improve treatment engagement in assessment and treatment of PTSD or knowledge about PTSD.

\section{Education and Engagement: Support and Family Education Program}

The Support and Family Education (SAFE) Program is a multisession educational program for families dealing with a wide range of mental illnesses (e.g., PTSD, major depression, bipolar disorder, schizophrenia) [17]. The intervention involves various family members (e.g., spouse, parent, siblings) in 14 sessions of educational material covering a range of topics for loved ones of a person with a mental illness and 4 sessions of skills training in problemsolving and minimizing stress. Because this is an educational program, the material is provided in once monthly 90 min workshops and attendance is based on family member interest. In a $5 \mathrm{yr}$ program evaluation, Sherman et al. reported that participant satisfaction was 18.2 out of a possible score of 20 (highest satisfaction) [18]. Caregivers attended a mean of 6.3 sessions; Sherman et al. noted that, given the monthly meeting schedule, they had a high rate of retention [18]. PTSD-focused sessions were the most wellattended sessions within the series, and 53 percent of caregivers of a loved one with PTSD attended more than one session. Finally, Sherman and colleagues reported positive correlations between the number of sessions attended and the understanding of mental illness, awareness of VA resources, and ability to engage in self-care activities. Negative correlations were found between the number of sessions attended and caregiver distress. No data regarding patient PTSD or other mental health outcomes for the family members or Veterans were reported. 
Table.

Couple/family interventions for posttraumatic stress disorder (PTSD).

Intervention
Education and Engagement
Support and Family Education

(SAFE) Program

Engagement

Generic Couple/Family Therapy

Behavioral Couple/Family

Therapy (BCT/BFT)

K’oach Program

Partner-Assisted Interventions

Lifestyle Management Course (LMC)
Brief Description

Key Citation

Sherman, 2003 [17];

SAFE Program is multisession educational program for families dealing with wide range of mental illnesses (e.g., PTSD, major depression, bipolar disorder, schizophrenia). Program welcomes various family members (e.g., spouse, parent, siblings). Includes 14 sessions of educational material covering range of cogent topics for loved ones of person with mental illness and 4 sessions of skills training in problem-solving and minimizing stress. Material is provided in once monthly 90 min workshops and attendance is based on family member interest. Little objective data reported on SAFE program; however, family members reported high satisfaction with program in one study and anecdotal reports indicate skills learned helped participants' families.

No empirical data on interventions specifically targeting concerned significant others to facilitate treatment engagement.

In randomized clinical trial, Glynn et al. tested version of BFT following individual cognitive-behavioral therapy [4]. This family treatment included (1) psychoeducation on PTSD that explicitly addresses relatives' expectations and coaches them on recognizing and reinforcing intermediate gains in service of long-term progress and (2) skills training in communication (i.e., constructive expression of feelings and empathic listening), problem-solving, and anger management training. BFT was delivered in 8 weekly 2 h sessions. Those receiving BFT and individual therapy evidenced significantly better interpersonal problem-solving skills than those receiving individual therapy only. BCT tested in other studies included goals of increasing positive interactions, improving communication, teaching problem-solving skills, and enhancing intimacy in intimate partners. These studies have generally revealed significant improvements in relationship functioning, but less effects on individual PTSD symptoms. K'oach program was monthlong, extensive, multifaceted treatment program developed in Israel. Wives of male Veterans were included at several points during program to learn communication skills, cognitive coping skills, and reinforcement methods to support husbands' positive behavior. Wives and family members participated in "family day" that included entertaining activities and increased positive interactions. During last $2 \mathrm{wk}$ of program, Veterans and wives participated in three couple groups during which they discussed common problems, improved communication and problem-solving skills, and promoted Veterans to view their partners as sources of support. These groups continued after treatment and served as self-help group. Little empirical research has been reported on efficacy of program. Some evidence that K'oach program improved relationship functioning, but not Veterans' PTSD symptoms.

LMC is intensive, structured group intervention for Veterans and their partners that consisted of $5 \mathrm{~d}$ of courses in residential setting led by counselors experienced in treating Veterans with PTSD. Intervention is based on cognitivebehavioral principles and conceptualizations of PTSD and was delivered to both members of couple simultaneously. Topics covered included education about PTSD, relaxation/meditation, self-care, diet and nutrition, alcohol use, stress management, communication, anger management, and problemsolving. In one study, program was shown to reduce anxiety, depression, and stress in both Veterans and their partners and PTSD symptoms in Veterans. Has not been shown to improve relationship satisfaction.
Sherman et al., 2006 [18]

Not applicable

Glynn et al., 1999 [4];

Cahoon, 1984 [25];

Sweany, 1987 [40]

Rabin \& Nardi, 1991 1992 [27]

Devilly, 2002 [9]
[26]; Solomon et al. 
JRRD, Volume 49, Number 5, 2012

Table. (cont)

Couple/family interventions for posttraumatic stress disorder (PTSD).

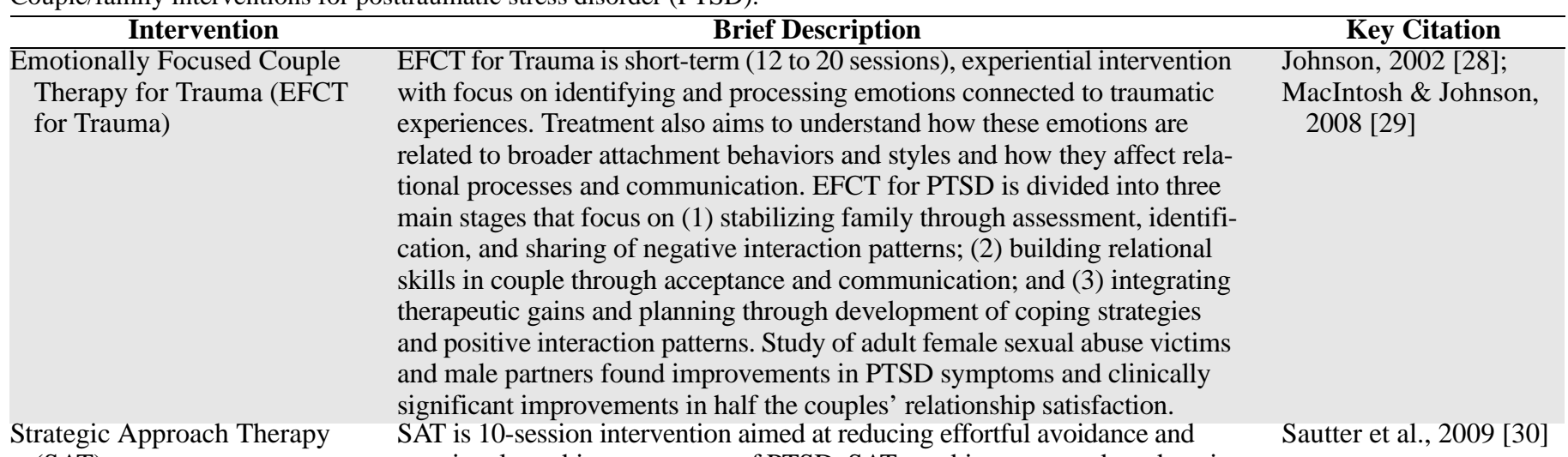

(SAT)

Cognitive-Behavioral Conjoint Therapy for PTSD (CBCT for PTSD) emotional numbing symptoms of PTSD. SAT combines partner-based anxiety reduction, behavior exchange, and stress inoculation techniques to gradually increase couples' exposure to anxiety-producing, avoided situations and positive emotional exchanges. Three broad treatment phases are (1) motivational enhancement and psychoeducation about PTSD, specifically avoidance symptoms and their effect on relationships; (2) relationship enhancement and increased emotional intimacy; and (3) partner-assisted anxiety reduction using graded exposures. Initial results from uncontrolled trial found improvements in behavioral avoidance and emotional numbing; no data reported regarding relationship satisfaction effects.

CBCT for PTSD is designed to simultaneously improve individual PTSD symptoms and enhance intimate relationship functioning. CBCT for PTSD consists of fifteen 75 min sessions comprising three phases: (1) education about PTSD and its effect on relationships and safety building, (2) communication skills training and couple-oriented in vivo exposures to overcome behavioral and experiential avoidance, and (3) cognitive interventions aimed at changing problematic trauma appraisals and beliefs that maintain PTSD and relationship problems (i.e., trust, power/control, and emotional and physical closeness). Data from uncontrolled trials with Veteran and community samples and initial results from randomized controlled trial of range of traumatized individuals provide evidence for improved PTSD symptoms, improved relationship satisfaction (especially in partners), and enhanced partner mental health and well-being.

*Schumm JA, Fredman SJ, Monson CM, Chard KM. Cognitive-behavioral conjoint therapy for PTSD: Initial findings for Operations Enduring and Iraqi Freedom male combat veterans and their partners. Am J Fam Ther. 2012. In press.

Currently, no published research that we are aware of has investigated the use of CSOs to engage Veterans with PTSD into treatment. Given the number of barriers that exist for Veterans with PTSD to present for assessment and treatment [19] and the number of CSOs who want to help but may not know the best way to help and/or may "help" in inadvertently detrimental ways (e.g., accommodation or codependent behaviors), this is an important way of utilizing family members in order to enhance service delivery. We are aware of at least one national effort, called "Coaching Into Care," that is a telephone-based support service designed to help family members of Veterans encourage distressed Veterans to access their VA healthcare benefits.
The focus of the service is specifically in cases of mental health issues. The intervention is designed to provide support to family members and help them plan and implement an informed, noncoercive approach when talking with a troubled Veteran about seeking or resuming VA mental health care. Initial program evaluation data suggest a modest increase in the engagement of the Veteran in mental health care after one or several telephone coaching sessions [20].

\section{Generic Couple/Family Therapy}

Behavioral couple/family therapy. In this article, we use the acronym BCT when referring to studies involving couples only and BFT for those studies involving a range of 
family members. Whether applied to couples or families more broadly, behavioral couple/family therapy (BCT/BFT) generally involves behavioral exercises to increase positive, reinforcing exchanges in couples and families, as well as communication skills training (i.e., sharing thoughts and feelings, problem-solving) [21]. Some interventions include a cognitive focus on partners' maladaptive standards and attributions applied to the relationship and to each other [22]. BCT has been identified as an efficacious practice for general couple distress according to American and Canadian Psychological Association Treatment Guidelines [23-24].

Two completed RCTs have tested variants of generic BCT/BFT with PTSD patients. Both were conducted with samples of male combat Veterans and their family members. As previously reviewed, in another published RCT including BFT after DTE, Glynn and colleagues found that those receiving DTE $\rightarrow$ BFT had significantly more improvements in interpersonal problem-solving than those who did not receive BFT [4].

Three other uncontrolled studies have examined group BCT with Veterans. Cahoon reported the results of a $7 \mathrm{wk}$ group BCT focused on communication and problemsolving training for male combat Veterans and their female partners [25]. Group leaders reported statistically significant improvements in Veterans' PTSD symptoms and coping abilities, and female partners reported significant improvements in marital satisfaction and problem-solving communication. The Veterans did not report improvements in problem-solving or emotional communication skills.

K'oach program. Results have been reported from the Israeli K'oach program, an intensive treatment program for male combat Veterans with PTSD in which wives were included at several points during the program [26-27]. This program included psychoeducation about PTSD, plus communication and problem-solving skills training for the couples. Minimal outcome data have been reported on this intervention; however, 68 percent of the male Veterans and their wives reported relationship improvements. Consistent with the focus of the intervention, no decreases in Veterans' PTSD symptoms were observed.

\section{Partner-Assisted Interventions: Lifestyle Management Course}

As discussed, Devilly described the results of an uncontrolled study of Australian combat Veterans and their partners who participated in an intensive weeklong residential group intervention that included psychoeducation about PTSD and symptom management techniques
[9]. At follow-up, both Veterans and their partners reported significant reductions in anxiety, depression, and general stress and Veterans reported a significant reduction in PTSD symptoms. Small improvements were also observed for anger and quality of life but not for relationship satisfaction.

\section{Disorder-Specific Interventions}

Emotionally focused couple therapy for trauma. Emotionally focused couple therapy for trauma (EFCT for Trauma) is a short-term (12 to 20 sessions), experiential intervention with a focus on understanding and processing emotions that are connected to the traumatic experience and broader attachment behaviors and styles that affect relational processes and communication [28]. EFCT for Trauma is divided into three main stages that focus on (1) stabilizing the couple through the assessment, identification, and sharing of negative interaction patterns; (2) building relational skills in the couple through acceptance and communication; and (3) integrating therapeutic gains and planning through development of coping strategies and interaction patterns. Qualitative case studies are reported in Johnson [28].

A study of 10 couples, including an adult female who had suffered child sexual abuse, provides initial support for the efficacy of EFCT for Trauma [29]. In this study, the couples completed between 11 and 26 sessions of therapy and completed assessments at pre- and posttreatment. The authors report that all the participants experienced at least one standard deviation worth of improvements on a clinician-administered measure of PTSD and half the participants self-reported clinically significant improvements in PTSD symptoms. Also, half the participants self-reported clinically significant improvements in relationship satisfaction. Three couples who reported decreased satisfaction and increased emotional abuse terminated their relationships during the course of therapy. The authors suggest that EFCT for Trauma may not be appropriate for couples in which emotional abuse exists.

Strategic approach therapy. Strategic approach therapy (SAT) is a 10-session manualized BCT developed by Sautter et al. [30] to target the avoidance/numbing symptoms of PTSD. Findings from six Veteran couples who completed the intervention include significant improvements in these symptoms according to patient, partner, and clinician ratings. Significant improvements also occurred in the Veterans' total PTSD symptoms, but not reexperiencing or hyperarousal symptoms. Relationship adjustment also significantly improved [31]. 
Cognitive-behavioral conjoint therapy for posttraumatic stress disorder. CBCT for PTSD is designed to simultaneously address individual PTSD symptoms and relationship problems [13]. CBCT for PTSD consists of fifteen 75 min sessions comprised of three phases: (1) treatment and education about PTSD and its impact on relationships and increasing safety, (2) communication-skills training and dyad-oriented in vivo exposures to overcome behavioral and experiential avoidance, and (3) cognitive interventions aimed at changing problematic trauma appraisals and beliefs most relevant to the maintenance of PTSD and relationship problems (i.e., trust, power/control, and emotional and physical closeness). Three uncontrolled studies with Vietnam Veterans (Monson et al. [10]), Iraq and Afghanistan Veterans (Schumm et al. ${ }^{*}$ ), and community members (Monson et al. [32]) and their romantic partners indicate improvements in PTSD symptoms and their comorbidities and some evidence of relationship improvements in couples who may or may not be clinically distressed at the outset of therapy (this is not an inclusion criteria for the therapy).

A wait-list controlled trial of CBCT for PTSD is nearly complete. This trial includes a sample of individuals with a range of traumatic events, including combat trauma, and different types of intimate couples (i.e., married, cohabitating, noncohabitating, same sex). The most recent results from this trial indicate significant improvements in PTSD and comorbid symptoms from pre- to posttreatment that are maintained at 3 mo follow-up. These improvements are on par with or slightly better than those found with individual treatments. Additional benefits of the therapy are significant improvements in relationship satisfaction (e.g., Monson [33]). CBCT for PTSD is undergoing initial testing for a range of CSOs and delivery in multi-CSO groups.

\section{DISCUSSION}

Some evidence exists that educational groups are associated with family members' greater knowledge about Veterans' mental health symptoms, VA resources, and decreased caregiver burden. There is not yet pub-

\footnotetext{
*Schumm JA, Fredman SJ, Monson CM, Chard KM. Cognitivebehavioral conjoint therapy for PTSD: Initial findings for Operations Enduring and Iraqi Freedom male combat veterans and their partners. Am J Fam Ther. 2012. In press.
}

lished research on interventions designed to incorporate CSOs to enhance engagement and retention in PTSD assessment and treatment. As expected given the target of the intervention, two RCTs of generic BCT or BFT with Veterans and their families have yielded improved relationship functioning, but provide variable evidence regarding significant improvements in PTSD symptoms. A partner-assisted BCT provides evidence for improvements in some symptoms of PTSD, but no evidence yet establishes its efficacy for improving relationship satisfaction. With regard to disorder-specific couple therapy, some data support the efficacy of EFCT for Trauma in couples, including a female partner with a history of childhood sexual abuse; no group-level data for Veterans with PTSD are available yet. Three uncontrolled trials and results from an ongoing RCT of CBCT for PTSD indicate that this therapy ameliorates PTSD symptoms, enhances intimate relationship satisfaction, and improves partners' individual mental health and well-being.

\section{CONCLUSIONS AND FUTURE DIRECTIONS}

Our most recent military engagements have been met with greater understanding of the multiple effects of PTSD on the individual and the Veteran's larger family unit. Appreciating the toll that PTSD and its comorbidities can have on family functioning, the VA was provided authority by Public Law 110-387, "Veterans' Mental Health and Other Care Improvement Act," in 2008 to include marriage and family counseling as a service for family members of all Veterans eligible for care. As a result, clinicians with expertise in couple and family therapy have been hired and training and dissemination efforts have been initiated to increase staff capacity to deliver evidence-based couple/family interventions. This represents an important step in providing Veterans and their family members with access to a range of interventions to improve their individual and relationship functioning.

We have presented a heuristic to help guide clinicians in their PTSD treatment planning and provision. Although there are no algorithms or empirically derived decision trees to identify the treatment or treatment category most appropriate for a given client, some general guidelines from our own thinking and practices may be useful in treatment planning. For example, if the Veteran has been unwilling to engage in treatment and the goal is to engage the Veteran or educate the CSO, the education/engagement interventions 
may be most appropriate. In some situations, generic couple/family therapy may be the treatment of choice. If Veterans with PTSD are engaged in trauma-focused treatment for PTSD, do not wish for their CSO to be integrated into that treatment, and they or their CSO are experiencing relationship distress, adjunctive generic couple/family therapy may be included in the treatment plan. Decreasing ambient stress caused by the Veteran's distressed relationships and enhancing social support may improve individual treatment outcomes (e.g., Price et al. [34], Tarrier et al. [7]). Generic couple/family therapy may also be pursued if the Veteran is unwilling or not yet ready to engage in trauma-focused psychotherapy for PTSD and is experiencing relationship distress. As reviewed, the skills taught in evidence-based generic couple/family treatments (e.g., conflict management, cognitive interventions) may have more diffuse effects in improving PTSD and decreasing the stress on the Veteran and CSO, thereby improving individual and relational functioning.

Partner-assisted interventions may be selected when the Veteran is involved in individual therapy and the therapist wishes to selectively include a supportive CSO to maximize treatment delivery (e.g., facilitating in vivo exposures to trauma-relevant cues). One cautionary note about this method of CSO inclusion comes from the partnerassisted agoraphobia treatment research [35]. We do not recommend partner-assisted interventions in cases in which the Veteran and CSO are experiencing relationship distress because of the potential for increased conflict associated with the CSO acting as surrogate therapist or coach.

Finally, in light of the accumulating evidence for the efficacy of PTSD-specific couple/family interventions to efficiently achieve multiple treatment outcomes, we recommend these treatments as a stand-alone option whenever a Veteran with PTSD and a partner are willing to engage in them. Some may be inclined to present these interventions when there is relationship distress. It is important to note that the existing disorder-specific interventions for PTSD have been tested in a range of satisfied couples (i.e., relationship distress has not been an inclusion criteria), with partners diagnosed with multiple comorbidities, to document benefits in individual and relational functioning. That said, if there is PTSD-maintaining behavior within the relationship between the Veteran and CSO (e.g., CSO accommodates avoidance behavior, which serves to maintain PTSD symptoms) or relationship distress, disorder-specific interventions may be especially indicated. In addition to achieving multiple outcomes, these treatments may confer additional service delivery. For example, Veterans have reported that if not for their CSOs' involvement, they would not have engaged in PTSD treatment. Again, these are recommendations based on clinical experience and some data; further research regarding these recommendations is needed.

The "family" portion of the "couple/family" label has been relatively neglected in research on PTSD interventions. More research is needed on interventions that apply to broader family functioning and the effects of parental mental health problems on children to better intervene at the "family" level. In addition, while a significant proportion of Veterans are married and have children, a sizable minority are not in committed romantic relationships and some are in committed same-sex relationships. We need to consider inclusion of a broader range of Veterans' close others when striving to enhance engagement, assessment, and treatment of PTSD.

Other important and growing demographic groups to consider in couple/family treatment for PTSD are female Veterans, aging Veterans who may present for the first time with PTSD or have changes in their PTSD presentation, and recently returning Veterans. Most of the research to date on Veterans and couple/family treatments for PTSD has investigated male Veterans with PTSD and their female partners. Research on Vietnam Veterans and the most recent cohort of Veterans suggests that female Veterans also have a myriad of family problems and, in fact, may be especially at risk for relationship problems and divorce (e.g., Gold et al. [36], Karney and Crown [37]). Furthermore, the developmental transition of retirement has been linked with relationship distress, as well as the appearance of PTSD symptoms [38]. Retirement is also a time when other age-related physical conditions and their treatment may increase relationship distress or exacerbate PTSD symptoms (e.g., cardiovascular incidents, cognitive changes). Finally, returning Veterans of recent conflicts are in great need of effective interventions that address interpersonal conflict in order to prevent further deterioration of relationships and development of chronic PTSD. Research already has documented rising reports of interpersonal relationship distress among these Veterans [39] and their expressed interest in greater family involvement in PTSD treatment (e.g., Batten et al. [3]). Questions also remain regarding the most effective aspects of the interventions we have reviewed. As the field identifies efficacious treatments, future dismantling studies may provide evidence about the essential components of these interventions. In addition, more research is 
needed on the most optimal mode of delivery (e.g., conjoint therapy delivered to individual dyads, in a group of dyads, via telehealth methodologies, paired with individual therapy).

We are delighted with the growing awareness and attention paid to the partners and family members who surround Veterans with PTSD. We anticipate that the next years will bring a number of important innovations in basic research, prevention, and treatment related to the families of Veterans with PTSD. These efforts will surely inform the next revision of the VA/DOD CPG and, in the meantime, hopefully our practices as clinicians, researchers, and policy makers to best serve Veterans with PTSD and their loved ones.

\section{ACKNOWLEDGMENTS}

\section{Author Contributions:}

Study concept and design: C. M. Monson, A. Macdonald,

A. Brown-Bowers.

Acquisition of data: C. M. Monson, A. Macdonald, A. Brown-Bowers. Analysis and interpretation of data: C. M. Monson, A. Macdonald, A. Brown-Bowers.

Drafting of manuscript: C. M. Monson, A. Macdonald,

A. Brown-Bowers.

Critical revision of manuscript for important intellectual content:

C. M. Monson, A. Macdonald, A. Brown-Bowers.

Obtained funding: C. M. Monson.

Administrative, technical, or material support: C. M. Monson, A. Macdonald, A. Brown-Bowers.

Study supervision: C. M. Monson.

Financial Interests: The authors have declared that no competing interests exist.

Funding/Support: This material was based on work supported in part by a grant from the National Institute of Mental Health (R34 MH076813).

\section{REFERENCES}

1. Monson CM, Taft CT, Fredman SJ. Military-related PTSD and intimate relationships: from description to theorydriven research and intervention development. Clin Psychol Rev. 2009;29(8):707-14. [PMID:19781836]

http://dx.doi.org/10.1016/j.cpr.2009.09.002

2. Renshaw KD, Blais RK, Caska CM. Distress in spouses of combat veterans with PTSD: the importance of interpersonally based cognitions and behaviors. In: Wadsworth SM, Riggs D, editors. Risk and resilience in U.S. military families. New York (NY): Springer; 2011. p. 69-84.
3. Batten SV, Drapalski AL, Decker ML, DeViva JC, Morris LJ, Mann MA, Dixon LB. Veteran interest in family involvement in PTSD treatment. Psychol Serv. 2009;6(3):184-89. http://dx.doi.org/10.1037/a0015392

4. Glynn SM, Eth S, Randolph ET, Foy DW, Urbaitis M, Boxer L, Paz GG, Leong GB, Firman G, Salk JD, Katzman JW, Crothers J. A test of behavioral family therapy to augment exposure for combat-related posttraumatic stress disorder. J Consult Clin Psychol. 1999;67(2):243-51. [PMID:10224735] http://dx.doi.org/10.1037/0022-006X.67.2.243

5. Lunney CA, Schnurr PP. Domains of quality of life and symptoms in male veterans treated for posttraumatic stress disorder. J Trauma Stress. 2007;20(6):955-64.

[PMID:18157892] http://dx.doi.org/10.1002/jts.20269

6. Monson CM, Rodriguez BF, Warner RA. Cognitive-behavioral therapy for PTSD in the real world: do interpersonal relationships make a real difference? J Clin Psychol. 2005; 61(6):751-61. [PMID:15546144] http://dx.doi.org/10.1002/jclp.20096

7. Tarrier N, Sommerfield C, Pilgrim H. Relatives' expressed emotion (EE) and PTSD treatment outcome. Psychol Med. 1999;29(4):801-11. [PMID:10473307] http://dx.doi.org/10.1017/S0033291799008569

8. Management of Post-Traumatic Stress Working Group [Internet]. VA/DOD clinical practice guideline for management of post-traumatic stress. Washington (DC): Department of Veterans Affairs, Department of Defense; 2010. Available from: http://www.healthquality.va.gov/ptsd/ptsd_full.pdf

9. Devilly GJ. The psychological effects of a lifestyle management course on war veterans and their spouses. J Clin Psychol. 2002;58(9):1119-34. [PMID:12209869] http://dx.doi.org/10.1002/jclp.10041

10. Monson CM, Schnurr PP, Stevens SP, Guthrie KA. Cognitivebehavioral couple's treatment for posttraumatic stress disorder: initial findings. J Trauma Stress. 2004;17(4):341-44. [PMID:15462542] http://dx.doi.org/10.1023/B:JOTS.0000038483.69570.5b

11. Mueser KT, Glynn SM. Behavioral family therapy for psychiatric disorders. New York (NY): Simon \& Schuster; 1995.

12. Carroll EM, Foy DW. Assessment and treatment of combatrelated post-traumatic stress disorder in a medical center setting. In: Foy DW, editor. Treating PTSD: cognitive-behavioral strategies. New York (NY): Guilford; 1992. p. 39-68.

13. Monson CM, Fredman SJ. Cognitive-behavioral conjoint therapy for posttraumatic stress disorder: harnessing the healing power of relationships. New York (NY): Guilford; 2012. Forthcoming.

14. Monson CM, Stevens SP, Schnurr PP. Cognitive-behavioral couple's treatment for posttraumatic stress disorder. In: Cor- 
ales TA, editor. Focus on posttraumatic stress disorder research. Hauppague (NY): Nova Science; 2005. p. 251-80.

15. Baucom DH, Shoham V, Mueser KT, Daiuto AD, Stickle TR. Empirically supported couple and family interventions for marital distress and adult mental health problems. J Consult Clin Psychol. 1998;66(1):53-88. [PMID:9489262] http://dx.doi.org/10.1037/0022-006X.66.1.53

16. Miller WR, Meyers RJ, Tonigan JS. Engaging the unmotivated in treatment for alcohol problems: a comparison of three strategies for intervention through family members. J Consult Clin Psychol. 1999;67(5):688-97.

[PMID:10535235] http://dx.doi.org/10.1037/0022-006X.67.5.688

17. Sherman MD. The Support and Family Education (SAFE) Program: mental health facts for families. Psychiatr Serv. 2003;54(1):35-37. [PMID:12509664] http://dx.doi.org/10.1176/appi.ps.54.1.35

18. Sherman MD, Sautter F, Jackson MH, Lyons JA, Han X. Domestic violence in veterans with posttraumatic stress disorder who seek couples therapy. J Marital Fam Ther. 2006;32(4):479-90. [PMID:17120520] http://dx.doi.org/10.1111/j.1752-0606.2006.tb01622.x

19. Kim PY, Thomas JL, Wilk JE, Castro CA, Hoge CW. Stigma, barriers to care, and use of mental health services among active duty and National Guard soldiers after combat. Psychiatr Serv. 2010;61(6):582-88. [PMID:20513681] http://dx.doi.org/10.1176/appi.ps.61.6.582

20. Sayers SL, Whitted P, Straits-Troster K, Hess T, Fairbank J. Families at Ease: a national Veterans Health Administration service for family members of veterans to increase veteran engagement in care. Annual Meeting of the Association for Behavioral and Cognitive Therapies; 2011 Nov; Toronto, Ontario, Canada.

21. Jacobson NA, Margolin G. Marital therapy strategies based on social learning and behavior exchange principles. New York (NY): Brunner/Mazel; 1979.

22. Epstein NB, Baucom DH. Enhanced cognitive-behavioral therapy for couples: a contextual approach. Washington (DC): American Psychological Association; 2002.

23. Canadian Psychological Association, Task Force on Empirically Supported Treatments. Empirically supported treatments in psychology: recommendations for Canadian professional psychology [Internet]. Ontario (Canada): Canadian Psychological Association; 2008 May. Available from: http://www.cpa.ca/documents/empiric front.html

24. Chambless DL, Hollon SD. Defining empirically supported therapies. J Consult Clin Psychol. 1998;66(1):7-18. [PMID:9489259] http://dx.doi.org/10.1037/0022-006X.66.1.7

25. Cahoon EP. An examination of relationships between posttraumatic stress disorder, marital distress, and response to therapy by Vietnam veterans [doctoral dissertation]. [Storrs]: University of Connecticut, Storrs; 1984.

26. Rabin C, Nardi C. Treating post traumatic stress disorder couples: a psychoeducational program. Community Ment Health J. 1991;27(3):209-24. [PMID:2055006] http://dx.doi.org/10.1007/BF00752422

27. Solomon Z, Bleich A, Shoham S, Nardi C, Kotler M. The "K'oach" project for treatment of combat-related PTSD: rationale, aims, and methodology. J Trauma Stress. 1992; 5(2):175-93.

28. Johnson SM. Emotionally focused couple therapy with trauma survivors: strengthening attachment bonds. New York (NY): Guilford; 2002.

29. MacIntosh HB, Johnson SM. Emotionally focused therapy for couples and childhood sexual abuse survivors. J Marital Fam Ther. 2008;34(3):298-315. [PMID:18717921] http://dx.doi.org/10.1111/j.1752-0606.2008.00074.x

30. Sautter FJ, Glynn SM, Thompson KE, Franklin L, Han X. A couple-based approach to the reduction of PTSD avoidance symptoms: preliminary findings. J Marital Fam Ther. 2009;35(3):343-49. [PMID:19522786] http://dx.doi.org/10.1111/j.1752-0606.2009.00125.x

31. Sautter FJ, Glynn SM, Armelie AP, Wielt DB, Casselli M. Couple-based treatment for PTSD in returning veterans. 27th Annual Meeting of International Society for Traumatic Stress Studies; 2011 Nov 15-17; Baltimore, MD.

32. Monson CM, Fredman SJ, Adair KC, Stevens SP, Resick PA, Schnurr PP, MacDonald HZ, Macdonald A. Cognitivebehavioral conjoint therapy for PTSD: pilot results from a community sample. J Trauma Stress. 2011;24(1):97-101. [PMID:21351166] http://dx.doi.org/10.1002/jts.20604

33. Monson CM. Cognitive-behavioural conjoint therapy for posttraumatic stress disorder: results from an ongoing randomized controlled trial. In: Monson CM, chair. Couplebased interventions for individual problems: Achieving multiple outcomes. Annual Meeting of Canadian Psychological Association; 2011 Jun; Toronto, Ontario, Canada.

34. Price M, Gros DF, Strachan M, Ruggiero KJ, Acierno R. The role of social support in exposure therapy for Operation Iraqi Freedom/Operation Enduring Freedom veterans: a preliminary investigation. Psychol Trauma. 2011;7.

35. Barlow DH, Mavissakalian M, Hay LR. Couples treatment of agoraphobia: changes in marital satisfaction. Behav Res Ther. 1981;19(3):245-55. [PMID:7295259] http://dx.doi.org/10.1016/0005-7967(81)90008-5

36. Gold JI, Taft CT, Keehn MG, King DW, King LA, Samper RE. PTSD symptom severity and family adjustment among female Vietnam veterans. Mil Psychol. 2007;19(2):71-81. http://dx.doi.org/10.1080/08995600701323368

37. Karney BR, Crown JS. Families under stress: an assessment of data, theory, and research on marriage and divorce 
in the military. Reported prepared for the U.S. Office of the Secretary of Defense. Los Angeles (CA): RAND Corporation; 2007.

38. Schnurr PP, Lunney CA, Sengupta A, Spiro A 3rd. A longitudinal study of retirement in older male veterans. J Consult Clin Psychol. 2005;73(3):561-66. [PMID:15982154] http://dx.doi.org/10.1037/0022-006X.73.3.561

39. Milliken CS, Auchterlonie JL, Hoge CW. Longitudinal assessment of mental health problems among active and reserve component soldiers returning from the Iraq war. JAMA. 2007;298(18):2141-48. [PMID:18000197] http://dx.doi.org/10.1001/jama.298.18.2141

40. Sweany SL. Marital and life adjustment of Vietnam combat veterans: a treatment outcome study [doctoral dissertation]. [Seattle]: University of Washington; 1987.
Submitted for publication September 9, 2011. Accepted in revised form February 28, 2012.

This article and any supplementary materials should be cited as follows:

Monson CM, Macdonald A, Brown-Bowers A. Couple/ family therapy for posttraumatic stress disorder: Review to facilitate interpretation of VA/DOD Clinical Practice Guideline. J Rehabil Res Dev. 2012;49(5):717-28. http://dx.doi.org/10.1682/JRRD.2011.09.0166

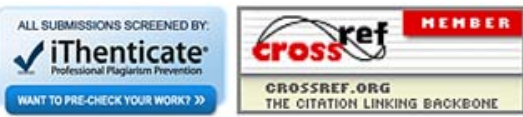

